\title{
Perancangan Buku Digital Interaktif sebagai Upaya Edukasi Jajanan Aman untuk Anak Sekolah Dasar Usia 7-9 Tahun
}

\author{
Annela Dhona Febrylian dan Denny Indrayana Setyadi \\ Departemen Desain Produk, Fakultas Teknik Sipil dan Perancanaan, Institut Teknologi Sepuluh \\ Nopember (ITS) \\ e-mail: denny@prodes.its.ac.id
}

\begin{abstract}
Abstrak-Pada masa sekarang ini, anak-anak sekolah dasar cenderung tertarik pada makanan jajanan yang memiliki warna, rasa dan bentuk yang menarik, namun jajanan tersebut belum tentu mengandung bahan yang aman dan sehat. Makanan jajanan sering dijumpai pada penjual di pinggir jalan, khususnya di sekitar sekolah dan jajanan di minimarket. Banyaknya jajanan yang tergolong tidak aman menimbulkan keresahan para orangtua. Badan Pengawas Obat dan Makanan (BPOM) telah menggalakkan beberapa edukasi jajanan pada berbagai media. Didukung oleh perkembangan teknologi dan informasi media pembelajaran yaitu aplikasi mobile, maka dirancang sebuah buku cerita interaktif berbentuk aplikasi mobile untuk anak sekolah dasar usia 7-9 tahun. Perancangan ini digunakan oleh anak sekolah dasar agar pemahaman anak tentang jajanan aman dapat disajikan secara menarik dan menyenangkan. Proses perancangan aplikasi ini dimulai dengan penggalian data primer, studi eksisting, proses prototyping, kemudian diuji cobakan kepada target audiens (usability testing). Hasil penelitian dianalisis hingga didapatkan konsep desain buku digital interaktif yang dapat mengedukasi anak di usia awal masuk sekolah dasar agar lebih selektif dalam memilih jajanan yang aman.
\end{abstract}

Kata Kunci-Edukasi, Buku Digital Interaktif, Jajanan Aman, Anak Usia 7-9 Tahun.

\section{PENDAHULUAN}

$\mathrm{K}$ EAMANAN pangan merupakan kondisi dan upaya yang diperlukan untuk mencegah bahan pangan dari kemungkinan cemaran biologis, kimia dan benda lain yang dapat mengganggu, merugikan dan membahayakan kesehatan manusia. Perilaku mengkonsumsi makanan pada anak usia sekolah harus diperhatikan secara cermat Badan Pengawas Obat dan Makanan (BPOM) Republik Indonesia. Tindakan pedagang yang memasukkan zat-zat berbahaya dalam jajanan sekolah bisa dipandang sebagai tindakan melanggar hak-hak anak untuk mendapatkan jaminan akan keamanan pangan yang dikonsumsinya[1].

Hasil penelitian Badan Pengawas Obat dan Makanan menunjukkan hampir separuh atau 44 persen jajanan anak yang dijual pedagang kaki lima tidak sehat dan mengandung zat aditif yang berbahaya[2]. Zat aditif sintetis lebih berbahaya bagi kesehatan manusia dibandingkan dengan zat aditif alami, apalagi jika dikonsumsi secara terus-menerus. Fenomena keracunan makanan jajanan sering terjadi pada kalangan anak usia sekolah.

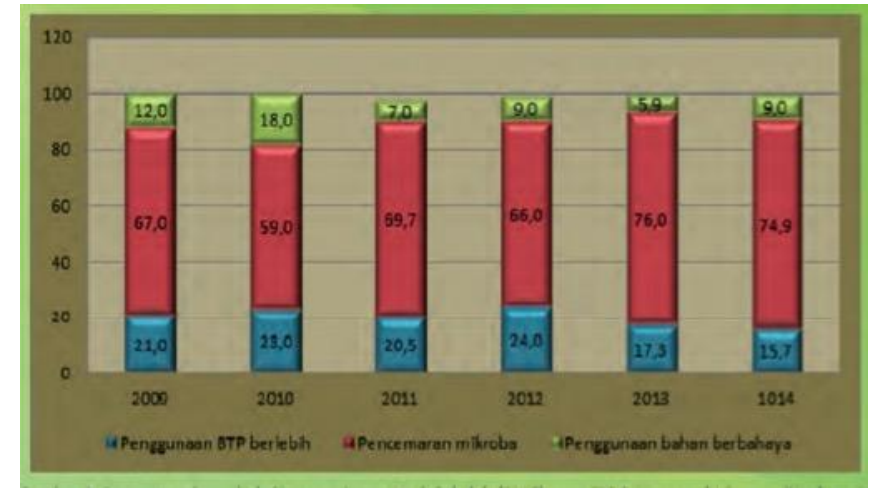

Gambar 1. Persentase penyebab PJAS yang tidak memenuhi syarat di Indonesia tahun 2009-2014.

Penyebab Pangan Jajanan Anak Sekolah (PJAS) dari tahun 2009-2014 yang paling tinggi disebabkan oleh pencemaran mikroba, Bahan Tambahan Pangan (BTP) berlebih dan penggunaan bahan yang berbahaya[3].

Terkait dengan fenomena makanan jajanan di sekolah, upaya promotif dan preventif telah dilakukan oleh BPOM telah dikemas dalam web klubpompi.pom.go.id yang berisi Pusat Informasi Pangan Jajanan Anak Sekolah yang ditargetkan khusus untuk anak-anak usia sekolah dasar. Upaya tersebut antara lain seperti Jambore Nasional Keamanan Pangan untuk Anak Sekolah, pengadaan lomba menulis cerita anak, mewarnai, menyanyikan jingle, membuat slogan dan lomba lainnya yang mengangkat tema Pangan Jajanan Anak Sekolah (PJAS). Namun, kegiatan yang berbentuk penyuluhan atau lomba tidak diadakan secara rutin. Informasi mengenai PJAS sangat diperlukan orang tua untuk memberikan wawasan secara intens kepada buah hatinya yang memiliki banyak waktu di sekolah dan terlepas sementara dari pengawasan orang tua. Hal tersebut membuat anak ketika di sekolah menjadi bebas memilih makanan jajanan yang mereka sukai tanpa memerhatikan bahaya kuman yang mungkin terkandung di dalamnya.

Maka dari itu, dibutuhkan sebuah media baru mengenai edukasi jajanan aman yang bertujuan untuk mengedukasi anak di usia awal masuk sekolah dasar agar lebih selektif dalam memilih jajanan yang aman. Penulis memilih buku digital interaktif berbentuk aplikasi mobile sebagai media pada perancangan ini, karena media tersebut merupakan salah satu alternatif media belajar yang dapat memuat konten multimedia di dalamnya dengan penyajian informasi lebih interaktif dan menarik. Teknologi multimedia mampu memberi kesan yang 
besar dalam bidang komunikasi dan pendidikan karena dapat mengintegrasikan teks, grafik, animasi, audio dan video. Multimedia dapat memberikan kemudahan umpan balik, antara pembimbing dengan yang dibimbing. Sesuai dengan karakteristik anak sekolah yang suka belajar sambil bermain, buku digital interaktif menampilkan bacaan yang memiliki visual lebih banyak dan dapat dimainkan.

Usia 7-9 tahun merupakan perkembangan awal anak untuk menerima edukasi mengenai keamanan makanan jajanan. Pada jarak usia tersebut kemampuan berfikir anak memiliki kemiripan, salah satunya yaitu kematangan berfikir. Mereka sudah siap untuk diajak berfikir kritis tetapi masih dalam konteks sederhana. Dengan media berbasis buku digital interaktif yang dikemas dalam aplikasi mobile, anak-anak di usia sekolah dasar diharapkan lebih mampu memahami pentingnya memilih makanan yang bergizi dan sehat untuk dikonsumsi dengan cara diperkenalkan informasi tentang jajanan aman dengan cara yang praktis, menyenangkan, mudah dipahami serta dapat diterapkan pada kehidupan sehari-hari terutama dalam memilih makanan jajanan[4].

\section{A. Batasan Masalah}

1. Buku digital interaktif pada perancangan ini merupakan media pembelajaran yang berbasis aplikasi mobile.

2. Media buku digital interaktif ini menyampaikan edukasi non-formal tentang jajanan aman.

3. Masalah yang diangkat mengenai fenomena anak sekolah dasar yang mengkonsumsi jajanan sembarangan.

4. Konten hanya terbatas pada edukasi memilih tempat membeli jajanan yang aman, memilih kemasan yang aman, serta memilih jajanan dengan bahan yang aman.

5. Studi kasus hanya dibatasi pada sekolah dasar di Surabaya.

\section{B. Rumusan Masalah}

"Bagaimana merancang buku digital interaktif jajanan aman sebagai media edukasi anak usia 7-9 tahun?"

\section{Tujuan}

Tujuan dari perancangan buku digital interaktif ini adalah mengedukasi anak di usia awal masuk sekolahdasar agar lebih selektif dalam memilih jajanan yang aman melalui media buku digital interaktif berbentuk aplikasi.

\section{METODOLOGI DAN ANALISIS PENELITIAN}

Berikut ini adalah alur proses riset dan desain dalam perancangan buku digital interaktifedukasi jajanan aman. Berikut adalah urutan alur penelitian yang dilakukan dalam perancangan ini.

\section{A. Metode Penelitian}

\section{1) In-depth Interview}

In-depth Interview dilakukan untuk mencari informasi lebih dalam mengenai akar dari permasalahan baik secara desain maupun non-desain. Saran dan masukan dari hasil wawancara kemudian akan dijadikan sebagai pertimbangan dalam pembuatan buku digital interaktif edukasi jajanan aman. Narasumber dalam wawancara ini yaitu Ibu Watiek Ideo selaku penulis buku cerita anak, Pak Eko A. Budi Darmawan dari pihak BPOM selaku stakeholder perancangan ini, dan Ibu
Nur Ilmiah, SKM selaku kepala seksi kesehatan lingkungan Dinas Kesehatan Surabaya dan beberapa pihak yang terkait dalam perancangan ini.

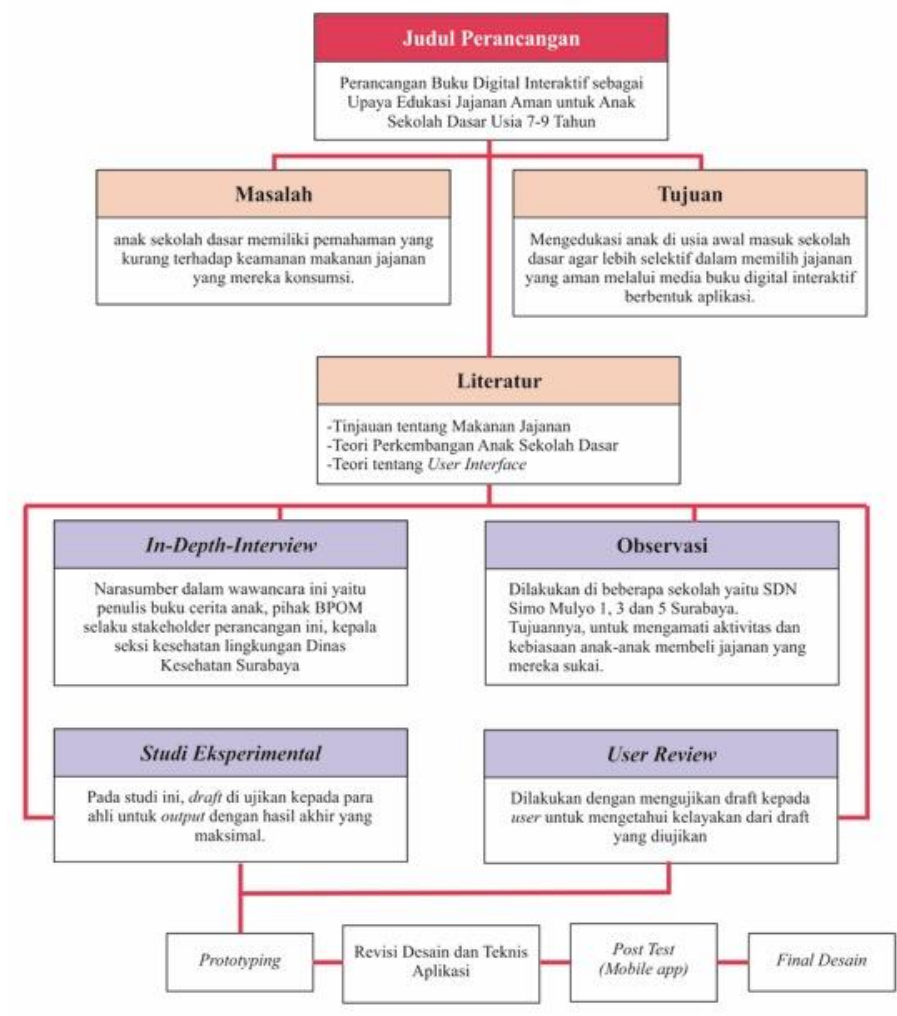

Gambar 2. Alur Proses Penelitian dan Desain Perancangan Buku Digital Interaktif.

2) User Review

User Review dilakukan dengan mengujikan draft berupa konsep perancangan kepada user yang fungsinya untuk mengetahui kelayakan dari draft yang diujikan, draft berfungsi sebagaimana mestinya dalam bentuk interaktif diujikan kemudian dengan metode usability studies ke para ahli.

3) Studi Eksperimental

Metode ini fungsinya kurang lebih sama dengan user review, namun bedanya draft diujikan kepada para ahli untuk output dengan hasil akhir yang maksimal baik dalam segi konten maupun teknis aplikasi.

\section{4) Observasi}

Observasi dilakukan di beberapa sekolah yaitu SDN Simo Mulyo 1, 3 dan 5. Tujuan observasi ini adalah untuk mengamati aktivitas dan kebiasaan anak-anak membeli jajanan yang mereka sukai. Hal tersebut dijadikan sebagai penguat data dan pembuatan konsep yatu dalam hal memutuskan jajanan apa yang akan dijadikan contoh pada cerita. Hasil dari observasi ini adalah anak-anak sekolah dasar memiliki kecenderungan gemar membeli jajanan yang berbentuk gorengan seperti telur gulung, pentol, telur goreng, cimol, sosis goreng, dan lain sejenisnya.

\section{5) Studi Literatur}

Dalam tahap ini, penulis menggunakan beberapa sumber literatur sebagai rujukan untuk menentukan konsep perancangan, antara lain konsep desain, media dan kriteria desain yang akan digunakan, serta untuk memperoleh informasi penting lainnya yang dapat dijadikan sebagai data pendukung dalam perancangan buku digital interaktif edukasi 
jajanan aman. Literatur yang digunakan yaitu seputar panduan tentang pangan sehat, zat aditif dalam makanan, pedoman keamanan pangan di sekolah dasar serta psikologi perkembangan anak.

\section{6) Studi Komparasi}

Metode ini dilakukan dengan mengkomparasikan subyek penelitian, yaitu aplikasi buku digital interaktif tentang edukasi jajanan aman. Media yang dijadikan sebagai eksisting adalah media sebagai acuan dan standar pembuatan perancangan ini, yaitu aplikasi sejenis dari beberapa negara di dunia seperti Riri-Wajah Baru Sungaiku, The Icky Mr. Fox, The Jungle Book, Birth of Krishna, Noah's Ark dan Even Monster Get Sick. Dari beberapa aplikasi tersebut yang dapat dijadikan acuan adalah dalam segi pengemasan cerita interaktif.

\section{7) Transformasi Karakter}

Pada metode ini, menghasilkan karakter perpaduan bantal dengan kucing. Pembentukan transformasi ini diikuti dengan metode-metode turunan yaitu objectives tree, matrix quality aplikasi eksisting, dan image chart, sehingga dihasilkan bentuk karakter yang lucu (gembul, pendek, mata besar, tak berleher), absurd (suara cempreng, baju kekecilan), polos (manja, suka makan).

\section{8) Computational Image and Animation}

Metode ini dilakukan untuk mempermudah proses pembuatan aset hingga terbentuknya animasi, agar tercipta hasil akhir yang sesuai dengan konsep yang diharapkan. Pada tahap pembuatan aset pada perancangan ini, diperlukan dua software yakni Adobe Illustrator CS 6 untuk dasar outline dan pewarnaan, kemudian dilanjutkan dengan penyempurnaan warna menggunakan teknik brush menggunakan Adobe Photoshop CC. Hasil keseluruhan aset kemudian diserahkan kepada programmer untuk ke tahap teknis.

9) Usability Testing/ Post Test

Metode ini dilakukan dengan mengujicobakan prototype kepada target audiens dan ahli. Pada tahap ini, manfaat yang didapatkan adalah tingkah laku target audiens dalam mengoperasikan aplikasi tersebut serta umpan balik dari para ahli.

\section{B. Teknik Sampling}

Pada perancangan buku digital interaktif, target audiens adalah anak sekolah dasar kelas 1, 2 dan 3 dari SDN Simo Mulyo 1, 3 dan 5 Surabaya. Pada tahap awal, target audiens diberikan wawancara seputar topik jajanan aman. Tahap berikutnya, anak-anak di berikan prototip perancangan berupa aplikasi yang ditampilkan di laptop. Pada tahap usability testing/ post test, anak-anak di ajak memainkan hasil akhir aplikasi dalam bentuk mobile.

\section{KONSEP DESAIN}

Konsep desain dari perancangan buku digital interaktif ini yaitu mempersuasi anak-anak agar tidak membeli jajan sembarangan melalui cerita interaktif berseri. Pada aplikasi ini, anak diajak untuk belajar sambil berimajinasi sesuai dengan apa yang mereka baca dan dengar. Konsep interaktif pada aplikasi ini ialah interactive touch digital book, yaitu target audiens disuguhkan dengan bacaan cerita yang setiap scene-nya terdapat gambar suasana full page mengenai cerita tersebut. Selain itu, dalam gambar tersebut di setiap objeknya dapat diinteraksikan dengan menyentuh atau menggeser objek, kemudian objek tersebut akan bergerak berbentuk animasi ringan yang dapat mendukung cerita yang dibawakan.

\section{A. Strategi Media}

Pemilihan aplikasi cerita interaktif sebagai media dalam perancangan ini bertujuan untuk menawarkan pilihan kepada anak-anak agar dapat menerima edukasi tentang jajanan aman dengan cara yang berbeda yakni melalui cerita interaktif yang dapat meningkatkan imajinasi anak melalui ilustrasi bergerak yang ditampilkan dalam sebuah aplikasi.

Buku digital interaktif berbentuk aplikasi mobile merupakan salah satu alternatif media belajar yang dapat memuat konten multimedia di dalamnya dengan penyajian informasi lebih interaktif dan menarik. Penelitian De Porter mengungkapkan bahwa manusia dapat menyerap suatu materi sebanyak $70 \%$ dari apa yang dikerjakan, $50 \%$ dari apa yang didengar dan dilihat (audio visual), sedangkan dari yang dilihatnya hanya $30 \%$, dari yang didengarnya hanya $20 \%$, dan dari yang dibaca hanya 10\% [5]. Teknologi multimedia mampu memberi kesan yang besar dalam bidang komunikasi dan pendidikan karena dapat mengintegrasikan teks, grafik, animasi, audio dan video. Pada aplikasi ini, beberapa elemen multimedia seperti elemen teks, visual, animasi dan audio terdapat di dalamnya.

\section{B. Strategi Komunikasi}

Strategi komunikasi yang digunakan sebagai pendukung dalam perancangan ini yaitu pendekatan moral, pendekatan artistik, dan pendekatan dwibahasa. Pendekatan moral berisi penyampaian informasi tentang sikap apa saja yang seharusnya mereka miliki untuk tidak salah memilih dan mengonsumsi jajanan adalah melalui hubungan sebab akibat. Pendekatan artistik berupa tampilan ilustrasi, animasi, layout serta tombol navigasi di dalam aplikasi yang memiliki grafis yang sesuai dengan karakteristik anak-anak. Pendekatan dwibahasa yakni bahasa Indonesia dan bahasa Inggris dengan kalimat yang ringan. Tujuannya yaitu agar konten yang disampaikan dalam bentuk cerita narasi tersebut lebih mudah dipahami oleh target audiens yaitu anak-anak.

\section{Alur Cerita}

Pada perancangan ini, keseluruhan cerita menggunakan alur maju yaitu terdiri dari tahap eksposisi, tahap awal konflik, tahap klimaks, tahap anti klimaks kemudian di akhiri dengan tahap denounmen. Setiap chapter menggunakan formula tersebut di dalam penyampaian cerita. Pada chapter 1 yang berjudul Jajanan dan Tempat yang Kotor, menceritakan tentang karakter utama yang membeli jajan pada penjual yang dekat sampah terbuka. Hal tersebut menyebabkan karakter utama sakit perut. Penyelesaian datang ketiga ibu karakter utama membuatkan minuman herbal agar tidak sakit perut dan membuatkan nasi goreng.

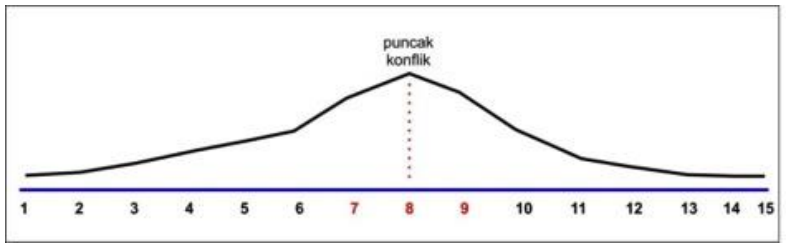

Gambar 3. Grafik alur cerita pada chapter 1 . 


\section{Kriteria Desain}

Kriteria desain pada perancangan buku digital interaktif diperlukan agar hasil akhir dapat diterima oleh target audiens yaitu anak-anak. Beberapa aspek penting yang harus diperhatikan agar buku digital interaktif dapat diterima oleh anak-anak bedasarkan ide dasar di antaranya adalah :

1) Warna

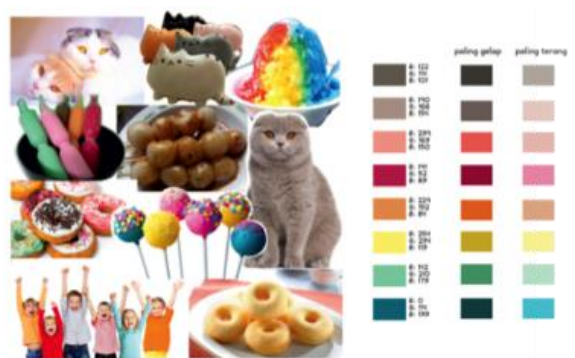

Gambar 4. Moodboard penentuan warna dalam perancangan buku digital interaktif.

Unsur warna yang digunakan dalam keseluruhan aplikasi ini diperoleh melalui moodboard yang isinya berhubungan dengan konten cerita. Pada gambar di atas merupakan moodboard beserta warna yang dihasilkan, yaitu memiliki kecenderungan ke arah soft, kalem, dan ceria karena mengandung unsur warna-warni.Penentuan warna berdasarkan moodboard mempermudah untuk membuat identitas visual yang konsisten.

\section{2) TypeSetting}

Jenis huruf yang sesuai dengan karakteristik anak-anak adalah jenis huruf yang jelas keterbacaannya. Pada aplikasi ini, huruf yang digunakan cenderung kepada jenis san-serif atau tak berkait. Selain digunakan dalam judul dan navigasi, jenis font san-serif ini juga diterapkan pada narasi berbentuk teks yang nantinya akan dibaca oleh audiens. Huruf yang digunakan dalam perancangan edukasi jajanan aman untuk anak sekolah dasar usia 7-9 tahun adalah sebagai berikut:

Tabel 1.

Tabel jenis huruf dan penerapannya pada buku digital interaktif

\begin{tabular}{cc}
\hline \hline Jenis Huruf & Penerapan \\
\hline Shablagoo Consended Italic & Judul aplikasi \\
Hangyaboly & Tulisan di bawah judul \\
Andika New Basic & Narasi cerita \\
Babycakes & Tombol Navigasi \\
\hline \hline
\end{tabular}

\section{3) Gaya Gambar}

Gaya gambar yang digunakan dalam perancangan buku digital interaktif ini adalah ilustrasi bergaya gambar kartun. Gaya kartun dipadukan dengan teknik pewarnaan digital menggunakan brush bertekstur dengan pencampuran gelap terang yang soft. Penggunaan gaya gambar tersebut dipilih untuk memenuhi kriteria desain anak yang lebih menyukai gambar kartun.

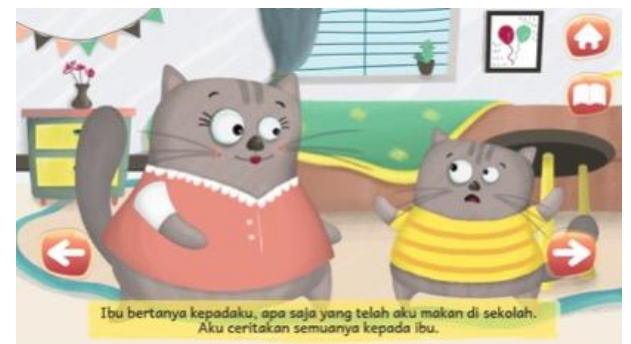

Gambar 5. Penerapan gaya gambar kartun pada buku digital interaktif.

\section{IMPLEMENTASI DESAIN}

\section{A. Visual Karakter Utama}

Karakter utama dalam aplikasi cerita interaktif ini berwujud kucing yang memiliki badan gemuk dan gerakannya squishy atau lentur dan dapat kembali ke bentuk semula. Karakter yang diadaptasi dari bentuk bantal ini memiliki ciri khas, yaitu hanya memakai baju atasan saja. Pakaian yang selalu muncul dalam cerita adalah pakaian sehari-hari berwarna kuning dengan garis-garis oranye dan seragam sekolah dasar lengkap dengan dasi dan topi. Berikut contoh karakter utama dengan pakaian sehari-hari (kiri) dan seragam sekolah dasar (kanan):

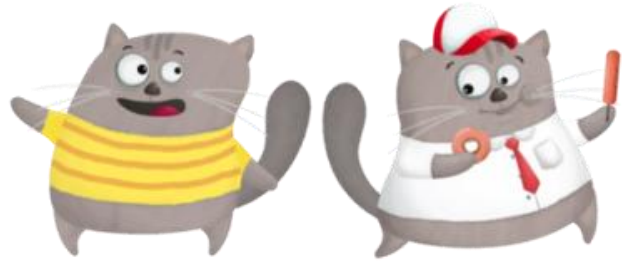

Gambar 6. Hasil akhir ilustrasi karakter utama.

\section{B. Karakter Pendukung}

Selain karakter utama, di dalam aplikasi ini juga terdapat karakter pendukung yaitu ibu dan penjual kue. Karakter pendukung utama yang sering muncul dan berhubungan langsung dengan karakter utama adalah ibu. Selain itu, terdapat juga karakter lain seperti kucing penjual dan lalat. Ciri khas dari karakter pendukung ini sama dengan karakter utama, yaitu hanya memakai pakaian atasan saja. Berikut visual dari ketiga karakter tersebut:
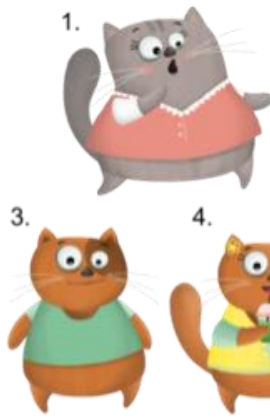

4
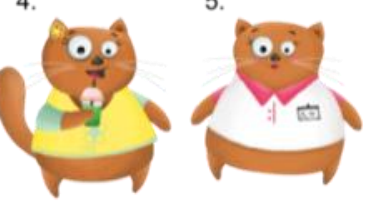

Gambar 7. Hasil akhir ilustrasi karakter pendukung.

\section{Objek Pendukung}

Objek pendukung pada aplikasi ini merupakan objek yang akan bisa diinteraksikan oleh user. Objek tersebut akan bisa bergerak ketika disentuh. Objek tersebut antara lain:

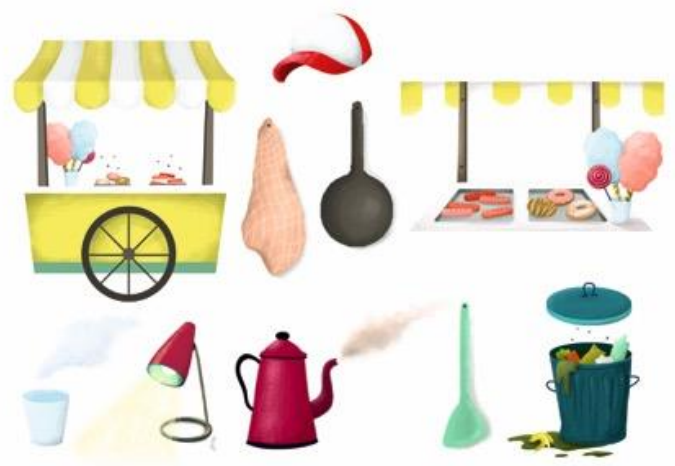

Gambar 8. Hasil akhir aset objek pendukung. 


\section{Latar Suasana}

Latar suasana yang terdapat pada aplikasi sebelum ditambahkan karakter dan objek yang bergerak memiliki tampilan sebagai berikut:

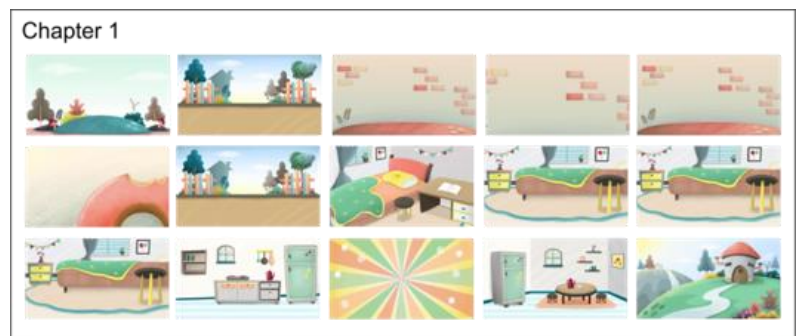

Gambar 9. Hasil akhir latar suasana chapter 1.

\section{E. Chapter Thumbnail}

Pada aplikasi ini, terdapat fitur memilih chapter dan scene secara pintas. Berikut adalah tampilannya:

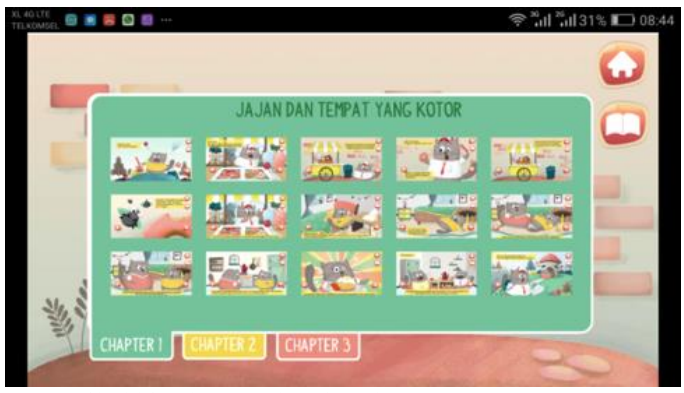

Gambar 10. Hasil akhir chapter thumbnail.

\section{F. Welcome Screen}

Tampilan utama pada aplikasi ini berupa welcome screen yang di dalamnya terdiri atas judul dengan latar belakang putih polos dan ikon pengaturan untuk memilih bahasa.
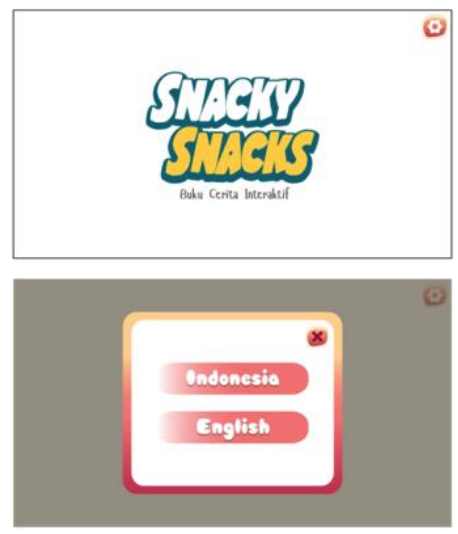

Gambar 11. Hasil akhir tampilan welcome screen.

\section{G. Homescreen}

Tampilan homescreen pada aplikasi ini berisi latar suasana rumah milik si karakter utama, Chilo. Kemudian menampilkan karakter utama yang sedang membawa donat dan gorengan, ia mengenakan seragam sekolah dasar. Selain itu, juga terdapat judul di sebelah kanan karakter, tombol mulai untuk masuk ke halaman baru, dan ikon pengaturan di pojok kanan atas.

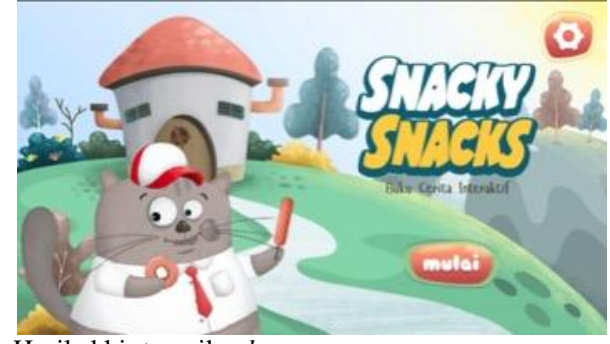

Gambar 12. Hasil akhir tampilan homescreen.

\section{H. Hasil Akhir Aplikasi}

Hasil akhir dari perancangan ini berupa aplikasi mobile dengan platform android. Di bawah ini beberapa hasil screenshot tampilan aplikasi:
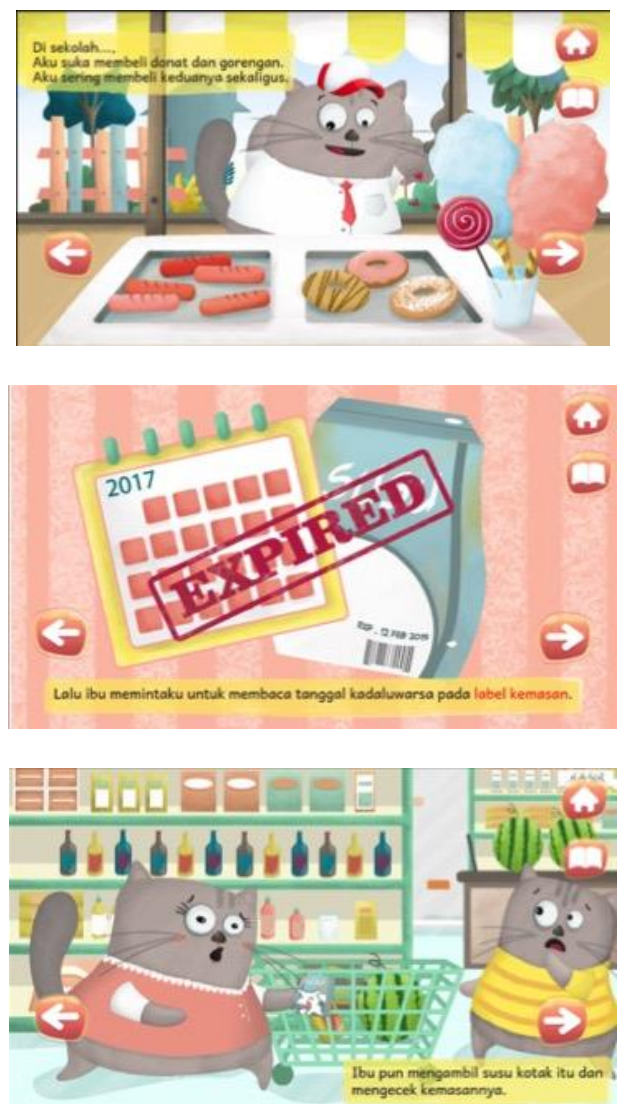

Gambar 13. Hasil akhir tampilan aplikasi pada android mobile.

\section{KESIMPULAN DAN SARAN}

\section{A. Kesimpulan}

Kesimpulan yang didapatkan dari hasil post test perancangan buku digital interaktif berbasis aplikasi mobile untuk anak usia 7-9 tahun dengan materi edukasi jajanan aman yaitu aspek penceritaan dengan cara pembabakan di setiap judul, serta alur cerita yang terdiri dari pengenalan, konflik dan penyelesaian sudah merepresentasikan anak-anak sebagai target audiens. Ilustrasi yang menggunakan figur fabel dan karakter yang terbentuk dari transformasi bantal menjadi 
kucing dengan latar suasana serta warna soft, serta adanya unsur animasi pada beberapa karakter dan objeknya. disukai oleh target audiens.

\section{B. Saran}

Aplikasi yang ber-platform android ini masih memiliki kekurangan, yaitu tidak dapat dioperasikan pada smartphone iOS. Sebuah peningkatan sangat diharapkan apabila masih memiliki waktu panjang di dalam proses pembuatan aplikasi ini. Dari segi animasi, peningkatan dalam segi animasi merupakan prioritas yang utama. Meskipun animasi sudah cukup mewakili ketertarikan anak-anak dalam menjalankan cerita interaktif ini, namun akan lebih baik lagi jika dikembangkan dengan memperbanyak animasi yang dapat menambah pengalaman pembaca dalam belajar sambil bermain.

Pada aplikasi ini, perlu ditambahkan beberapa scene yang berisi informasi atau pengetahuan berbentuk pesan kuncian pada setiap chapter-nya, bertujuan agar pembaca dapat mengingat scene kuncian tersebut. Pada perancangan ini, diharapkan dapat menghasilkan pula media turunan berupa animasi berseri agar dapat dijadikan sebagai alternatif lain sekaligus sebagai media promosi aplikasi ini agar lebih berkembang sehingga edukasi mengenai jajanan aman ini dapat didistribusikan lebih luas lagi.

\section{DAFTAR PUSTAKA}

[1] Anonimus, "Inilah Zat-zat Berbahaya di Jajanan Sekolah," Kompasiana, 2016.

[2] Anonimus, "Jajanan Anak Paling Berbahaya Versi BPOM," Tempo, Sep2016.

[3] Departemen Kesehatan, "Infodatin-Situasi Pangan Jajanan Anak Sekolah," 2016.

[4] W. Ideo, "Media Edukasi Cerita Interaktif yang Tepat untuk Anak Sekolah Dasar," 2016

[5] Anonimus, "Peranan Multimedia dan Alat Peraga dalam Pembelajaran," Kompasiana, 2017. 